Cambridge University Press

978-0-521-86249-3 - Nezhat's Operative Gynecologic Laparoscopy and Hysteroscopy, Third Edition

Edited by Camran Nezhat, Farr Nezhat and Ceana Nezhat

Excerpt

More information

\title{
$1 \quad$ HISTORY OF MODERN OPERATIVE LAPAROSCOPY
}

\author{
Barbara J. Page, Jaime Ocampo, Mario Nutis, and Anthony A. Luciano
}

\section{UNREASONABLENESS REDEFINED}

The reasonable man adapts himself to the world; the unreasonable one persists in trying to adapt the world to himself. Therefore all progress depends on the unreasonable man.-George Bernard Shaw

One of the greatest transformations within the history of surgery has been the paradigmatic shift away from open surgery and into the realm of operative video-laparoscopy, an approach that truly captured all that minimally invasive surgery was meant to mean. Many have described the advent of operative video-laparoscopy as a change to surgery as "revolutionary to this century as the development of anesthesia was to the last century." [1]

Indeed, video-endoscopy is today the most common surgical procedure performed by gynecologists, colonoscopists, and gastroendoscopists.[2] As for our own discipline, gynecologic laparoscopists were some of the earliest believers in the new way. Indeed, by 1986, it was estimated that more than 1 million laparoscopic sterilizations were being performed in the United States alone.[3] Today, gynecologic operative video-laparoscopy has freed millions of women from the era when debilitating, multiple laparotomies were the norm for even mild pelvic pathologies.

\section{NEZHAT AND THE ADVENT OF ADVANCED OPERATIVE VIDEO-LAPAROSCOPY}

However, getting to this point of general acceptance - a process that is not even complete yet - actually took years of persistent insistence and ingenuity. To actually breathe life into video-laparoscopy, an entirely new way of operating had to be envisioned and accepted into the fold of convention. Yet, to convince an entire surgical discipline to relearn how to perform surgery was no walk in the park. We all know, of course, that attempting to convince surgeons to do anything against their will is a headache in the making. But especially to force upon their heads a change so radical - that of shifting their sacred line of vision - was like courting a collision with catastrophe.

An outsized catalyst was needed to rend surgeons loose from the mighty clasp of custom. It was Camran Nezhat, considered the "founding father" of operative video-laparoscopy, who would use his visionary foresight and virtuoso surgical skill to bring this concept clamoring out of its dream-state and headlong into the realm of reality.

To achieve this, Nezhat rigged together video cameras intended for other uses and began operating off the monitor in the late 1970s, which then allowed him to perform advanced procedures never before done by the laparoscope. For the first time, laparoscopic treatment of extensive endometriosis involving extragenital organs was shown to be possible when Nezhat presented his work at the Annual Meeting of the American Fertility Society in 1985. A year later, his early clinical results on the subject were published in the Journal of Fertility \& Sterility under the title of "Surgical treatment of endometriosis via laser laparoscopy." After demonstrating the safety and feasibility of performing these complicated surgeries laparoscopically, Nezhat predicted that if such a complicated and extensive disease as endometriosis could be treated laparoscopically, then almost all other pathologies could be managed in that way, too, as long as a cavity existed or could be created in the body.

When all was said and done, Nezhat's conceptual breakthrough would revolutionize modern abdominal and pelvic surgery, overturning in its wake almost 200 years of endoscopic tradition. Talk about rocking the boat; boy would there be dues to pay before this uber-idea could claim its place at the helm of the minimally invasive movement.

\section{THE NATURAL ORDER OF THINGS?}

Of course, today all of this may seem so natural, so evolutionarily inevitable, like the story of man walking upright. Yet, operative video-laparoscopy, a concept that now seems almost prosaic in its self-evident appeal, was not so obvious a solution during the late 1970s, nor was it an idea that came gently into being.

Looking back, one actually finds that the opposite was true. Rather, the birth of operative video-laparoscopy was more like a case of gravity defied. It was like suggesting a baseball player look the other way right when the ball is pitched, totally counterintuitive.

To get a feel for just what Nezhat was up against in trying to convince the surgical world to believe in his ideas, let us take a quick trip back in time to review the status of operative laparoscopy as it stood in the 1970s, in terms of the types of procedures being performed, available technologies, and cultural mindsets that hindered its development.

\section{MAROONED IN MEDIOCRITY: THE EARLY $1970 S$ JUST BEFORE VIDEO-LAPAROSCOPY}

Powerful indeed is the empire of habit. -Publilius Syrus

\section{Operative Procedures Achieved by the 1970s}

The late 1970s skepticism concerning gynecologic operative laparoscopy is not so clearly spelled out in other historical 
Cambridge University Press

978-0-521-86249-3 - Nezhat's Operative Gynecologic Laparoscopy and Hysteroscopy, Third Edition

Edited by Camran Nezhat, Farr Nezhat and Ceana Nezhat

Excerpt

More information

2 - Barbara J. Page, Jaime Ocampo, Mario Nutis, and Anthony A. Luciano

accounts. Many have made the inaccurate claim that gynecologists had "fully embraced" laparoscopy as a standard modality by the 1970s. [4,5] While there is a grain of truth in this with respect to diagnostic laparoscopy, for advanced operative procedures, the story was quite different. This can be established by reviewing the literature and textbooks of this era, where one can plainly see that operative laparoscopic procedures being performed were essentially no more advanced than those which had been introduced nearly 50 years earlier by endoscopy's early-20th-century pioneers: draining cysts, lysis of adhesions, taking biopsies, electrocautery, and tubal ligations.

\section{Aspiration of Ovarian Cysts - But Not Their Removal}

The history of draining cysts laparoscopically serves as a perfect example to track these operative plateaus. As early as the 1920s, the American laparoscopic pioneers Ordnoff and Bernheim were some of the first to demonstrate how successful the "peritoneoscope" (aka, laparoscope) was for this procedure. Jacobaeus was also able to drain ascites in the abdomen in the 1910s, a laparoscopic procedure similar in nature. Yet, more than 50 years later, some of the most popular manuals and textbooks of the 1970s and 1980s - Frangeheim's Endoscopy and Gynecology, TeLinde's Operative Gynecology, AAGL Manual of Endoscopy, Hulka's Textbook of Laparoscopy, Baggish's Atlas of Contract Hysteroscopy and Endoscopy, Wheeless' Atlas of Pelvic Surgery - all specifically direct laparoscopists to focus only on aspiration as the standard practice.[6-11] Surgical removal was made possible as a routine practice as a result of video-laparoscopy. Today, of course, clinical data demonstrate that up to $40 \%$ of these cysts do refill, indicating, therefore, that surgical removal is the preferred standard.[12]

\section{Tubal Sterilizations}

As for the endoscopic superstar of the 1970s - tubal sterilizations it actually got its start back in 1936, when Boesch performed the world's first documented laparoscopic tubal sterilization using electro-cauterization.[13] Naturally, the technique has been per-

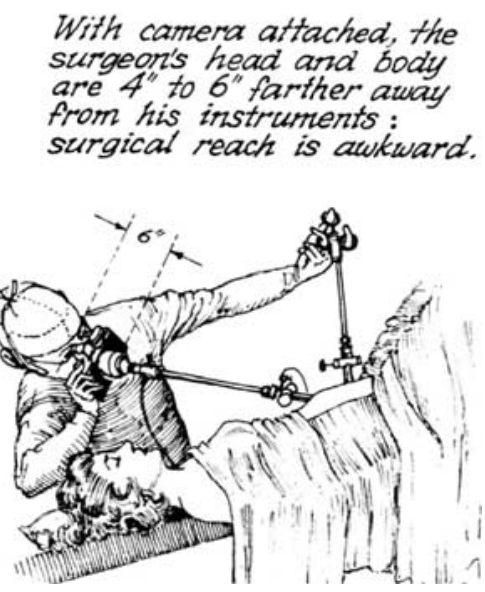

Figure 1.1. Surgeon with old laparoscopic setup still being published in laparoscopic books in the 1980s. Picture adopted from Textbook of Laparosopy by Jaroslav Hulka, 1985. fected over the years. Yet, by the 1970s, conceptually the procedure had not changed much from its 1930s debut.

Indeed, with the exception of contributions from the era's few virtuosos, such as Palmer, Semm and Mettler, Steptoe, Cohen, and Gomel, our entire discipline seemed stalled for what felt like was going to be forever at tubal sterilizations, as if it were the final frontier.

\section{Близок локоток, да не укусишь - Blizok lokotok, da ne ukusish}

Impossible, you might say! Fifty years without a new operative procedure? How could this be? After all, eye-popping technological advances were proliferating at an astonishing clip during this era; fiber optics, automatic insufflators, electronically controlled thermo-coagulators. Yet, here we were, in the late 20th century, with men and monkeys flying to the Moon and back, while we laparoscopists were still stuck back at the farm, doing mainly routine diagnostics. It seemed to be a clear case of Blizok lokotok, $d a$ ne ukusish. This old Russian proverb, translated as "your elbow is close, yet you can't bite it," was an apt description for the times because, with the new technologies enabling video-laparoscopy even more, we were so elbow-close to breaking through and past the old ways. Yet, paradoxically, we were so far away from the "bite" because, as Nezhat and other pioneering laparoscopists of this era soon discovered, confronting psychological resistance to change was the far more difficult task to overcome.[14]

\section{ANOTHER CONUNDRUM}

There was another conundrum to overcome: New surgical techniques had to be invented that could accommodate being done in the new closed, video-laparoscopic manner. Doing a procedure endoscopically that was actually designed to be done via laparotomy presented one of the most formidable problems. In short, there were essentially no textbooks or protocols established that would have demonstrated how to make these procedures feasible laparoscopically. Some innovations were beginning to pour through the pipeline; Semm and Mettler's extracorporeal Roeder's loop was one such example. $[15,16]$ Yet these contributions still did not resolve the majority of the problems having to do with achieving more advanced procedures.

In short, each procedure normally done via laparotomy would have to be re-invented. This process was naturally one of trial and error, a factor that especially exposed Nezhat and other laparoscopic pioneers to some harsh criticism in the early days.

\section{An Overview of the Times - TV, Video, and Light Source Technologies}

As for the nature of endoscopic technologies, many precursors to video had been established for many years prior to the 1970s. Cinematography and television had actually been used modestly in a handful of surgical centers since the late 1930s. By the 1950s, Japanese pioneers from Hayashida Hospital, Uji, Fukami, and Suginara, developed one of the earliest endoscopic cameras, the gastrocamera,[17] while in 1953 Cohen and Guterman introduced their Cameron cavicamera.[18] 
Cambridge University Press

978-0-521-86249-3 - Nezhat's Operative Gynecologic Laparoscopy and Hysteroscopy, Third Edition

Edited by Camran Nezhat, Farr Nezhat and Ceana Nezhat

Excerpt

More information

Some of the most sensational moments in endoscopy's history came with the debuts of the world's first television and color film broadcasts by French pioneers; Palmer's 1955 color film debut of the first live laparoscopy; and, in the same year, the world's first television broadcasts of live bronchoscopies, achieved separately by the French bronchoscopists Soulas and Dubois de Montreynaud.[19] Within a few years, Frangenheim of Germany would produce his famous 1958 color film of a gynecologic laparoscopic surgery, a feat that reverberated throughout the world of gynecologic laparoscopists for years to come.[20]

By 1960, Inui, Berci, and others had either invented or collaborated with industry to bring miniaturized video endo-cameras into endoscopy. However, all of these systems were definitely not designed with advanced operative video laparoscopy in mind. For instance, Berci's 1962 article was one of the earliest to mention both "TV" and endoscopy" in the title. While this article did an excellent job of delineating the latest TV technologies, nevertheless its singular focus was on the ways in which the new imaging technologies would enhance documentation and teaching capabilities; there is no mention of changing the method of performing endoscopic procedures, with the goal of advancing laparoscopy's operative potential.[21]

Even as late as 1977, Berci revisited the role of TV and video devices - referred to as "teaching attachments" - as technologies to enhance teaching only.[22,23] Figures 1.1 through 1.5 from this same 1977 article also clearly show that the most recent cameraequipped endoscopes were still designed to be used in the old way, with endoscopists peering awkwardly through the scope. A similar attachment, called a "multiple tube medical television camera," highlighted in a 1977 American Association of Gynecologic Laparoscopists (AAGL) conference also demonstrates this well-entrenched trend.[24-25]

In other words, while some of the technological rudiments to support video-laparoscopy had been in existence for at least 40 years, the most crucial missing link was not technological in nature, but rather was an issue of missing imagination. The conceptual idea of combining these technologies and using them in an entirely different way had been entirely overlooked until Nezhat's unique contribution.

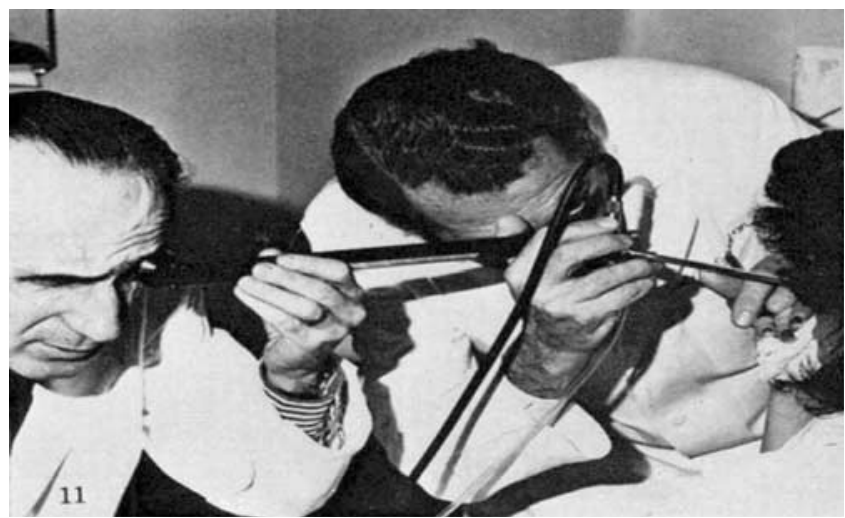

Figure 1.2. Dr. Berci peering through a teaching attachment in 1977. Although Dr. Berci had very innovative ideas, Dr. Nezhat was the first person to operate off a videomonitor. Photo adopted from Berci, G. (1977). Present and future developments in endoscopy. Proceedings of the Royal Society of London.

\section{A PARADOX - POOR RESOLUTION ALMOST FOILS THE THOUGHT}

This background review has missed one vital but paradoxical point: Even with these newly emerging optic and video technologies, Nezhat's idea was still too advanced for the era's technologies to support. At the time of Nezhat's awakening to the magic of operating upright, operating off the monitor was barely feasible. The early generation optics and video systems (before digital was perfected) did not yet produce the level of high pixel resolution that we have become accustomed to today. And, despite the superior illumination afforded by the most recent fiber optics and Hopkins lens systems, the quality of light had not advanced to a level where images could be efficiently split toward the monitor. As recently as 1977, Berci made a point to mention the inadequate nature of light sources, stating that "Illumination sources are in a chaotic state." [26] These combined technical deficiencies meant that the images shown on the monitor were so grainy that for most they proved to be indiscernible; definitely not clear enough to support the notion of operating off images. This is why so many surgeons were initially against the idea, because it was quite disorienting to view barely discernible images emanating from a low-resolution, two-dimensional screen positioned several feet away from both surgeon and patient!

\section{BACKLASH TO LAPAROSCOPY FOR SECOND TIME IN THE 20TH CENTURY}

As if these obstacles were not enough, gynecologic laparoscopy in the United States was experiencing another season of discontent, just beginning to surface in the late 1970s. Of course, as usual with the story of laparoscopy, this is completely paradoxical, for the discipline did experience some very dramatic leaps forward during this era, at least symbolically. For example, by the mid-1970s training in laparoscopy had been added to "all major gynecologic residency programs" in Europe.[27] By 1981, the American Board of Obstetricians and Gynecologists followed suit and made laparoscopic training a required component of U.S. residency programs. The number of procedures being performed annually also skyrocketed. By about 1973, some sources state that between 6 million and 7 million endoscopic procedures were being performed annually in the United States alone.[28] Other reports show that from 1971 to 1976, laparoscopic sterilizations increased from a mere $1 \%$ to an astonishing 60\%. [29] Although such statistics on the quantity of surgical procedures are notoriously difficult to verify, based on our research these appear to be reasonable estimates.

Yet at the end of the day, the majority of operative procedures were still limited to simple tasks, which translated to millions of female patients continuing to be subjected to multiple laparotomies for even mild cases of endometriosis. This stall in the progression toward more advanced procedures was, in part, caused by growing concerns about complication rates associated with out-patient laparoscopic sterilizations, which had rapidly grown in popularity in just a few short years.

A growing backlash toward all things laparoscopic developed in earnest, and articles forewarning of high complication rates began to seep into the literature. One of the first such articles to gain national attention was published by the well-respected 
Cambridge University Press

978-0-521-86249-3 - Nezhat's Operative Gynecologic Laparoscopy and Hysteroscopy, Third Edition

Edited by Camran Nezhat, Farr Nezhat and Ceana Nezhat

Excerpt

More information

\section{4 - Barbara J. Page, Jaime Ocampo, Mario Nutis, and Anthony A. Luciano}

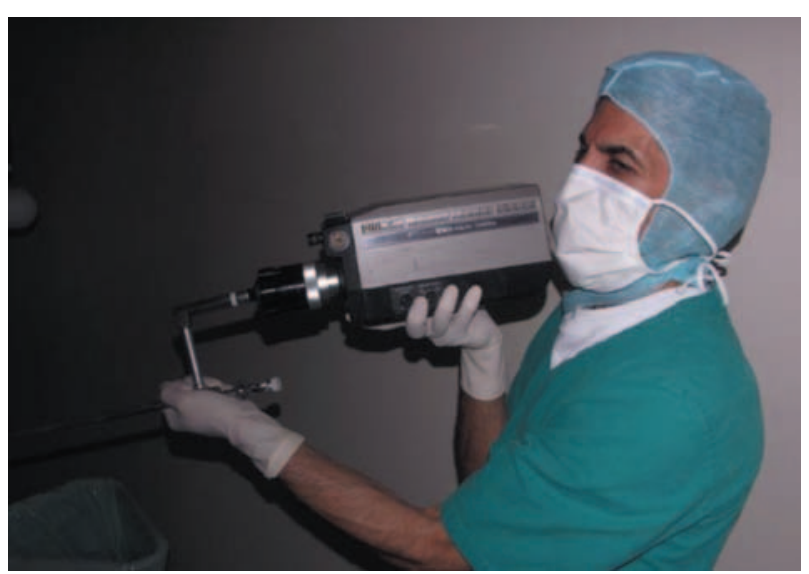

Figure 1.3. One of the first cameras used for video-laparoscopic surgery by Cameron Nezhat, MD.

founder of the AAGL, Jordan Phillips, whose 1977 report outlining in stark detail the estimated complication rates associated with laparoscopic tubal sterilizations struck a raw nerve within surgical communities and served for a time to temper enthusiasm. [30] Indeed, failed sterilizations became the second leading cause of lawsuits for ob-gyns in the United States, only after those associated with pregnancy complications. [31]

Another example of the ambivalence over the scope's role in more advanced operative procedures can be found in one of AAGL's most memorable meetings, at which Semm had been invited to demonstrate the types of operative procedures he envisaged for his "pelviscopy." "Kurt Semm's pelviscopy presentation struck people in that meeting as going too far," recalls Soderstrom, one of the founding members of AAGL. The title of this debate, called "Laparoscopy is replacing the clinical judgment of the gynecologist," also perfectly captured the unease about allowing the scope to advance beyond diagnostics.[32]

Soon thereafter, urgent congressional hearings and other governmental advisory panels were called into session to address concerns about the rapid technological changes affecting endoscopic medical devices, in particular, and medical technologies, in general. Symbolic actions were taken against laparoscopy, beginning most conspicuously with the Congressional Health Device Act passed in 1976. Later, in 1981, the Centers for Disease Control (CDC) in Atlanta issued a very strong public rebuke over patient deaths apparently linked to unipolar laparoscopic sterilization procedures. [29] Because the medical community tends to err on the side of caution, such adverse reports - whether exaggerated or not - were nearly the death-knell for laparoscopic innovation in those days.

\section{THE FROZEN TUNDRA OF BUFFALO - THIS IS YOUR BRAIN ON IMAGINATION}

Necessity knows no law except to conquer. - Publilius Syrus

And thus it unfolded that, for the second time in the 20th century, interest in laparoscopy had soared to the heights of unfathomable popularity, only to plunge back down to Earth once its inherent limitations were revealed after the veil had been lifted. An epic tale indeed was in the making, as it seemed our laparoscope's once rising star of shiny, happy brilliance was on the verge of being reduced to a garish glare. The revivalist hey-day that American laparoscopists had so enjoyed from 1965 to 1975 had been nearly neutralized by the end of the 1970s. [32]

In other words, the timing could not have been worse to introduce such a radically new concept as that of advanced operative video-laparoscopy!

All the same, Nezhat remained imperturbable. These heavy realities were no match for his hidden reserves of moxie; he boldly pushed past the raucous ramble of naysayers, forcing a reckoning with minimally invasive surgery as the new reality. So, how did it all begin?

Amidst the frozen tundra that is Buffalo, New York, in midwinter, there was a kindling mind, ablaze with great visions that soon would take the surgical world by storm. But how did videolaparoscopy develop from the imagination of this young physician just starting his residency? And, by the way, what audacity! How did he find the courage to disagree with senior surgeons - at risk to his own just-blooming career - and take on the entire surgical world? Very gracefully, of course.

More than anything, the "how" came from the "why": Nezhat was driven to help ease the pain of his patients, who had been forced to endure 6- to 12-inch incisions into their abdomens for even the mildest of pathologies. In witnessing the extreme pain and suffering of his patients, their long convalescence, and the serious and numerous complications arising out of laparotomies, Nezhat believed that with just minor alterations almost all of this unnecessary suffering could be averted. It seemed clear to Nezhat that one of the most significant hindrances was the positioning of the surgeon in relation to the scope. The whole contraption left him contorted in the most unnatural of positions: bent-over sideways, with an assistant blindly holding the scope in place while the surgeon tried in vain to verbally direct its positioning.

He knew that if only he could find a way to circumvent the physical limitations posed by peering through the scope's singular eyepiece that the scope's surgical capabilities could then be extended into more advanced operative procedures. Practicing in the lab late at night, he realized that one might be able to perform surgery standing upright by watching the monitor.

With the concept now firmly in his head, Nezhat began the art of rigging together whatever equipment he could find to make this vision come true.

Nezhat recounts those early days:

Early on, vascular and neurosurgeons had had success using cameras for microsurgery. So, hoping to learn from their successes, I approached my colleagues in these disciplines. Their willingness to spend time demonstrating this technology was very fruitful. Of course, we ran into unusual logistical dilemmas trying to adapt this technology. Many strange configurations were attempted before achieving any degree of success. [Eventually though], we were able to convert an old camera used in their disciplines into an awkward but nevertheless functioning addition to the scope. - Nezhat, C, Presidential Speech, September 2005, JSLS (Figure 1.3)

Despite this precarious start, Nezhat was able to collaborate with other disciplines, a factor which became crucial in further 
Cambridge University Press

978-0-521-86249-3 - Nezhat's Operative Gynecologic Laparoscopy and Hysteroscopy, Third Edition

Edited by Camran Nezhat, Farr Nezhat and Ceana Nezhat

Excerpt

More information

developing these ideas.[34] Nezhat attributes this multidisciplinary facet as having been a vital source of endless inspiration. Endometriosis especially led him to work with other specialties because it commonly affects many different organs, especially the gastrointestinal (GI) and genitourinary (GU) tracts. The contributions of Dr. Earl Pennington, a pioneering colorectal surgeon, and Drs. Rottenberg and Green, both urologists, were especially noteworthy, as they guided Nezhat through very challenging procedures that had never been achieved laparoscopically before.[34] Nezhat recalls, "Colorectal surgeon, Earl Pennington, and urologist, Howard Rottenberg, were always at our side." Also, patients with endometriosis have high rates of endometriomas that sometimes can have the appearance of malignancy. Therefore, from the very beginning, contributions from colleagues in gynecologic oncology were of critical importance. In this area, the guidance of Drs. Benedict Benigno and Matthew Burrell was absolutely invaluable. Through their vision and willingness to share their expertise, a better understanding of how to recognize and manage malignancies laparoscopically was achieved.[35]

As for new suturing methods, only a few modifications were needed. For the most part, Nezhat was able to convert the same microsurgical techniques for open surgeries as were taught by pioneers in treating endometriosis such as Drs. Robert Frankling of Houston, Texas, and Ron Batt of Buffalo.[37] Before switching to video-laparoscopy, suturing laparoscopically was a feat extraordinarily difficult to achieve while hunched over the scope. In fact, this factor was one of the main hindrances that had made earlier attempts at operative laparoscopy so awkward, unsuccessful, and, ultimately, unpopular.

\section{“FOREVER-SCOPY”}

Operative video-laparoscopy was certainly not without its flaws. And we would not want to delude the reader by providing only the pretty pictures of its past. Indeed, one of its least attractive features initially was the extra time it took to perform some of the advanced procedures. As Nezhat recalled, "They used to call laparoscopy 'forever-scopy."” For instance, laparoscopic ectopic pregnancy surgeries were taking 4-5 hours initially, while Nezhat recalls that his first - and also the world's first - radical hysterectomy and paraeortic and pelvic lymphadenectomy by videolaparoscopy actually took 7 hours. This added time factor was not helping convince anyone that the video-laparoscopic method was better or safer than open surgery.[36] Of course, even some laparotomies took up to 7 hours. But, the new method naturally was judged more harshly than classical standards.

Because of this time factor stemming from the very steep learning curve, the effectiveness of video-laparoscopy was difficult to assess at first. Early reports showed laparoscopy to have higher complication rates than laparotomies, although these results were attributable mainly to inexperience.

\section{COLLABORATION WITH INSTRUMENT MAKERS}

To overcome these inherent deficiencies standing in the way of the new technique, Nezhat began a fruitful relationship of collaboration with Karl Storz and other surgical instrument companies.

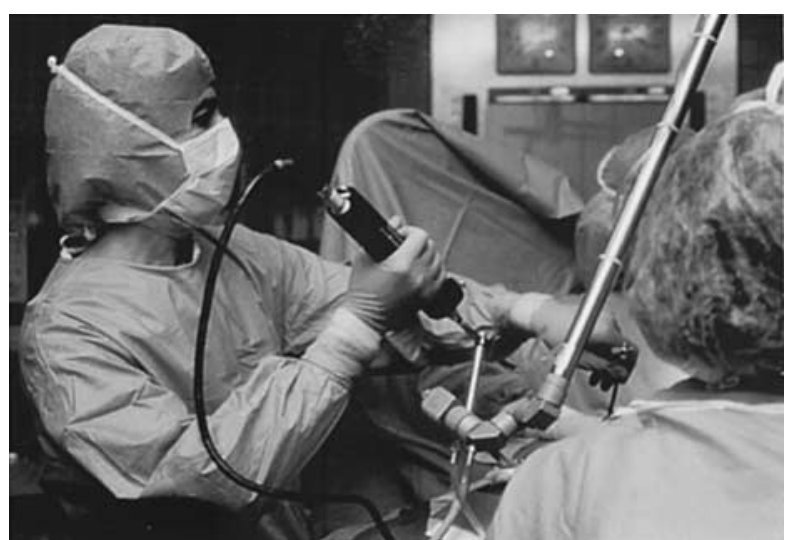

Figure 1.4. Camran Nezhat doing videolaparoscopy in early 1980.

Using those same old clunky cameras borrowed from the neuro and vascular surgeons, Nezhat was able to show the company representatives that operating off the monitor could work. After hours in the operating room, eventually Storz and other company representatives were also convinced of the scope's greater potential and they began producing new cameras and light sources customized for operative video-laparoscopy.

Today, working together with companies in this fashion might be discouraged. Yet, without this early support and free-spirited exchange of ideas between engineers and surgeons, poor visualization and other technological hindrances certainly would have persisted as formidable conceptual and technological divides. [37]

\section{DELAYS IN PUBLICATIONS}

Despite collecting verifiable clinical proof to the safety and efficacy of video operative laparoscopy, at first no journal would accept Nezhat's early manuscripts on the subject.[12]

It took several years, but finally his debut articles on these never-before-seen laparoscopic surgeries were published in 1986. $[13,38]$ From this point, Nezhat was able to continue to demonstrate -this time to a larger audience - that other complex surgeries were finally possible (Figure 1.4). Indeed, between the years of 1984 and 1989, Nezhat forced a reconsideration of all that was thought possible when he and his colleagues became the first to successfully perform such complex surgeries as:

- the first laparoscopic treatment of multi-organ, extensive, stage iv endometriosis, affecting the GI and GU; [39-49]

- the first laparoscopic bowel surgery and resection with Pennington; [39,42, 44, 45, 49, 50]

- the first laparoscopic ureter resection and ureterouretrostomy with H. Rottenberg and B. Green; $[43,45,48]$

- the first laparoscopic radical hysterectomy with paraortic and pelvic node dissection with M. Burrell and B. Benigno; [51, 52]

- the first laparoscopic bladder resection with $\mathrm{H}$. Rottenberg; $[43,45,48]$

- the first laparoscopic vesicovaginal fistula repair with H. Rottenberg; [53]

- the first laparoscopic rectovaginal fistula repair with J.A. Bastidas; 
Cambridge University Press

978-0-521-86249-3 - Nezhat's Operative Gynecologic Laparoscopy and Hysteroscopy, Third Edition

Edited by Camran Nezhat, Farr Nezhat and Ceana Nezhat

Excerpt

More information

\section{6 - Barbara J. Page, Jaime Ocampo, Mario Nutis, and Anthony A. Luciano}

- the first laparoscopic ovarian cystectomy in second and third trimesters of pregnancy; [54]

- the first laparoscopic-assisted surgery (laparoscopically assisted myomectomy);

- the first laparoscopic Burch procedure;[55]

- the first laparoscopic treatment of ovarian remnant with E. Pennington and H. Rottenberg; [56]

- the first laparoscopic sacral colpopexy;[57]

- the first laparoscopic treatment of diaphragmatic endometriosis lesions with H. Brown; [58]

- the first laparoscopic management of a leaking inferior mesenteric artery with C. Zarins; [59]

- the first laparoscopic coronary reanastomosis in a porcine model; [49]

- $\quad$ and the first laparoscopic management of dermoid cyst.[60]

Acceptance and publications on these firsts by Nezhat and his colleagues often faced numerous rejections and/or lagged 3 to 5 years after the initial procedures were performed, due to either resistance from journal editors to such new-fangled ideas, or for preference to publish the work of those in academia rather than those in private practice. In any case, before 1990, Nezhat and his colleagues had already performed laparoscopically nearly all the major procedures involving the bowel, bladder, and ureter, which in the past had only been accomplished via laparotomy.

\section{“AGONY IN THE GARDEN" - THE ERA OF HOSTILITY}

Scandal has ever been the doom of beauty. - book ii, properties

Like a rite of passage, the quintessential pioneer story would not be complete without an element of abject suffering to startle us out of our imaginative reverie. Like Semm, Muhe, and others, Nezhat endured many years of doubt before his ideas became accepted. In terms of endoscopy's long history, this was not surprising. There had always existed an element of resistance since the time of Bozzini, if not earlier. Resistance to operative video-laparoscopy was especially fierce for it forced surgeons - for the second time in the 20th century - to lose two vital sensory mechanisms: tactile and direct visualization. [61] These changes seemed to be the tipping point that drove the final stake into ancient surgical practices, bringing to the fore a 21 st-century approach that few were actually ready to embrace. Indeed, so suspect was the new surgical revolution that Nezhat and his brothers had their academic integrity called into question.

Just a few years ago, in 2002, a lay media frenzy went so far as to label Nezhat's work "bizarre," "barbaric," and akin to "medical-terrorism." Forced now to answer to this misinformed media frenzy, Stanford University was essentially left with no choice but to act in the most politically expedient manner by launching a highly publicized, formal investigation of Nezhat's work, issuing in the process a temporary suspension to appease the public outcry. After lengthy investigations - and to the surprise of no one in the know - Nezhat's work was found to be free of any misconduct whatsoever, cleared by the highest authorities from Stanford University, the U.S. State Supreme Court, and the California and Georgia State Medical Boards. How ironic it is today that, quietly, all the studies are pouring forth which confirm
Nezhat's initial impressions of the advantages of operative videolaparoscopy. Those same procedures, pioneered by Nezhat and his team considered so controversial just a few years ago, are now encouraged to be performed by the most prestigious journals. A 2004 editorial from the New England Journal of Medicine states, "Surgeons must progress beyond the traditional techniques of cutting and sewing ... to a future in which ... minimal access to the abdominal cavity [is] only the beginning." [62]

\section{CONCLUSION}

History may be servitude, history may be freedom - from "Little Gidding," TS Eliot

Sometimes history can become an unbearable weight. Operating off the monitor and inventing the accompanying advanced procedures were the crucial links which allowed our discipline to be set free from hundreds of years of history, peering directly through a tube, specula, or scope. By demonstrating the scope's boundless potential, Nezhat hit the groundbreaking grand slam that drove laparoscopy home toward its true operative potential.

Perhaps of even more lasting significance, switching to the monitor set off an intense scientific and philosophical debate about just where the upper bounds - if any - of operative laparoscopy should end. It forced a reconsideration of the entire field of surgery, a change that called for every aspect of surgical methodologies to be thoroughly scrutinized. And it was not strictly the category of surgery that was reevaluated. Rather, questions arose having to do with a wide range of aspects concerning medicine, patient rights, and disease-states. New concepts relating to pain management for patients emerged as one of the most important changes to have come about due to the minimally invasive movement. As well, an eventual rethinking in expectations about surgical outcomes arose. Complications once considered unavoidable in the days of open surgery were suddenly reevaluated and revised in the minimally invasive era.

Still, as gynecologic laparoscopists, our advocacy work to perfect and promote minimally invasive surgery is not done. There are still too many patients who are enduring needless open procedures. For example, in 1997 66.8\% of hysterectomies performed in the United States were done via laparotomy. Nevertheless, humankind is closer than ever to truly being able to perform the most advanced operative surgeries through the least traumatic incisions. For this reason, the nearly complete triumph of minimally invasive surgery - with video-laparoscopy leading the wayhas turned out to be one of the greatest achievements of 20thcentury medicine. More than that, it transformed into one of the world's most important human rights movements by insisting on greater and more democratized standards in healthcare, a change that touched the lives of millions of patients who had suffered too long in the shadows of silence.

\section{REFERENCES}

1. www.sls.org, Marelyn Medina, MD, Rio Grande Regional Hospital (McAllen, TX).

2. www.sls.org, Marelyn Medina, MD, Rio Grande Regional Hospital (McAllen, TX). The trouble with trocars, quote from M. Kavic in Nov 2001. 
Cambridge University Press

978-0-521-86249-3 - Nezhat's Operative Gynecologic Laparoscopy and Hysteroscopy, Third Edition

Edited by Camran Nezhat, Farr Nezhat and Ceana Nezhat

Excerpt

More information

3. Gomel, V. Surgical textbook introduction.

4. Sgambati, SA \& Ballantyne, GH. Minimallyinvasive surgery in the diseases of the colon and rectum: the legacy of an ancient tradition. In: Jager RM Wexner S, Laparoscopic Colectomy, Churchill \& Livingstone. New York. 1995. pp 13-23.

5. Gunning, JE. The history of laparoscopy. Jour of Repr Med, 1974, 12:6.

6. Frangeheim H. Endoscopy and gynecology. In The Range and Limits of Operating Laparoscopy in the Diagnosis of Sterility, Phillips, JM, ed. Downey, CA: AAGL, 1978.

7. TeLinde's Operative Gynecology, Lippincott Williams \& Wilkins,

8. Martin DC, ed. AAGL Manual of Endoscopy. , 1988.

9. Hulka, JF Textbook of Laparoscopy, Orlando, FL:Grune and Stratton, Inc., 1985.

10. Baggish, MS. Atlas of Contact Hysteroscopy and Endoscopy. Urban \& Schwarzenberg, 1982.

11. Wheeless, CR. Atlas of Pelvic Surgery, Lippincott Williams \& Wilkins, 1988.

12. Nezhat C, Crowgey S, Garrison C. Surgical treatment of endometriosis via laser laparoscopy. Fertility and Sterility, 1986; Vol 25, No 6, pp 778-783.

13. Boesch PF. Laproskopie. Schweiz Z Krankenh Anstaltw 1936; 6:62.

14. Bruhat MA, Mage G, Manhes H.: Use of $\mathrm{CO}_{2}$ laser by laparoscopy. In Laser Surgery III. Proceedings of the Third International Congress on Laser Surgery, I. Kaplan, editor. Tel Aviv, Jerusalem Press, 1979, p 225.

15. Semm K, Mettler L. Technical progress in pelvic surgery via operative laparoscopy. Am J Obstet Gynecol. 1980;138(2):121-7.

16. Semm K: The endoscopic intra-abdominal suture. Geburtshilfe Frauenheilkd. 42:56, 1982.

17. Uji T, Shirotokoro T and Hayashida T: Gastrocamera. Tokyo Med. J., 61:135, 1953 J. Japan Med. Ass., 1954; 31:681.

18. Cohen M. Laparoscopy, Culdoscopy, and Gynecolography. Philadelphia:WB Saunders, 1970.

19. Soulas A.: Televised bronchoscopy. Presse Med. 1956; 64:97.

20. Frangenheim H. Laparoscopy and Culdoscopy in Gynaecology. 1972; London: Butterworth, 1972.

21. Berci G., Davids J.: Endoscopy and television. B.M.J.1962; 1: 1610.

22. Berci G. Present and future developments in endoscopy. Proc. R. Soc. Lond. 1977. B. 195, 235-242

23. Olsen V, Berci G. Teaching attachments. Endoscopy. 1976. New York: Appleton-Century-Crofts.

24. Phillips, JM. Endoscopy in Gynecology. AAGL Proceedings of the Third International Congress on Gynecologic Endoscopy, 1977; 488-489.

25. Berci G. Flexible fiber endoscopes, Figure 2, Endoscopy Today. Mar 1972; 111-113.

26. Berci G. Present and future developments in endoscopy. Proc. R. Soc. Lond. 1977. B. 195, 235-242.

27. Litynski GS. Highlights in the history of laparoscopy.1996; Barbara Bernert Verlag.

28. Berci G. Endoscopy Today, 1972; vol 51, Nos 2 and 3: 64-70.

29. Soderstrom RM. A history of the American Association of Gynecologic Laparoscopists. The Journal of the American Association of Gynecologic Laparoscopists; 2001; Vol 8(4).

30. Phillips JM. Complications in laparoscopy. Int J Gynaecol Obstet. 1977;15:157-162.

31. Hulka JF. Foreword to Textbook of Laparoscopy. 1985; Grune \& Stratton.

32. Nezhat C. Personal correspondence files; rejection letters for the technique of video-laparoscopy and operating off the monitor.

33. Mahnes H. A History of Laparoscopy, Acceptance Speech, Recipient of SLS Excel Award, 2003.

34. Nezhat F, Nezhat C, Pennington E, Ambroze W, Jr.: Laparoscopic segmental resection for infiltrating endometriosis of the rectosigmoid colon: a preliminary report. Surg Laparosc Endosc, 1992, 2(3):212-216.

35. Journal of Society of Laparoendoscopic Surgeons, Presidential Speech, C. Nezhat, Sept 2005.

36. Shushan A, Mohamed H, Magos AL. How long does laparoscopy surgery really take? Lessons learned from 1000 operative laparoscopies. Hum Reprod. 1999; 14(1):39-43.

37. Nezhat C. Videolaseroscopy: A new modality for the treatment of endometriosis and other diseases of reproductive organs. Colposcopy \& Gynecologic Laser Surgery, 1986, 2(4): 221224.

38. Nezhat C, Crowgey S, and Nezhat F. Videolaseroscopy for the treatment of endometriosis associated with infertility. Fertility and sterility. 1989; 51(2): 237-40.

39. Nezhat $C$, and Nezhat FR. Safe laser endoscopic excision or vaporization of peritoneal endometriosis. Fertility and sterility, 1989; 52(1), 149-51.

40. Nezhat CR, Nezhat FR, and Silfen, SL. Videolaseroscopy. The $\mathrm{CO}_{2}$ laser for advanced operative laparoscopy. Obstetrics and gynecology clinics of North America. 1991; 18(3), 585-604.

41. Nezhat F, Nezhat C, \& Pennington E. Laparoscopic proctectomy for infiltrating endometriosis of the rectum. Fertility and sterility, 1992;57(5), 1129-32.

42. Nezhat CR, and Nezhat FR.. Laparoscopic segmental bladder resection for endometriosis: a report of two cases. Obstetrics and gynecology, 1992; 81(5 (Pt 2)), 882-4.

43. Nezhat C, Nezhat F, Pennington E, et al. Laparoscopic disk excision and primary repair of the anterior rectal wall for the treatment of full-thickness bowel endometriosis. Surgical endoscopy. 1994;8(6), 682-5.

44. Nezhat, Camran. A safe approach to Laparoscopic Excision of Serosal and Subserosal Endometriosis, Endometriosis of the Bladder, Ureter, Rectovaginal Septum and Rectum. Annual Meeting of AAGL September 1989.

45. Nezhat C. Advanced Laparoscopic Treatment of Endometriosis. Annual Meeting of AAGL, Sept 1989.

46. Nezhat F, Nezhat C, Videolaseroscopy for the treatment of infiltrative rectovaginal septum, endometriosis and posterior cul-de-sac nodularity. Annual Meeting of AAGL, Nov 1990.

47. Nezhat CR, Nezhat F, Nezhat CH. Operative Laparoscopy (minimally invasive surgery): State of the art. J. Gynecol Surg 1992;8:111141.

48. Seidman DS, Nezhat C. Letter-to-the-Editor: Is the laparoscopic bubble bursting? The Lancet, Feb 241996.

49. Nezhat, C, Nezhat, F, Ambroze, W, et al. (1993). Laparoscopic repair of small bowel and colon. A report of 26 cases. Surgical endoscopy, 7(2), 88-9.

50. Nezhat, CR, Nezhat, FR, Burrell, MO, et al. (1993). Laparoscopic radical hysterectomy and laparoscopically assisted vaginal radical hysterectomy with pelvic and paraaortic node dissection. Journal of gynecologic surgery, 9(2), 105-20.

51. Nezhat, CR, Burrell, MO, Nezhat, FR, et al. (1992). Laparoscopic radical hysterectomy with paraaortic and pelvic node dissection. American journal of obstetrics and gynecology, 166(3), $864-5$.

52. Nezhat, CH, Nezhat, F, Nezhat, C, et al. (1994). Laparoscopic repair of a vesicovaginal fistula: a case report. Obstetrics and gynecology, 83(5 Pt 2), 899-901.

53. Nezhat, F, Nezhat, C, Silfen, SL, et al. (1991). Laparoscopic ovarian cystectomy during pregnancy. Journal of laparoendoscopic surgery, $1(3), 161-4$.

54. Nezhat C, Nezhat F, Nezhat CH. Laparoscopic Burch procedure. Operative laparoscopy (minimally invasive surgery): state of the art. J Gynecol Surg. 1992; 8:111-141. 
Cambridge University Press

978-0-521-86249-3 - Nezhat's Operative Gynecologic Laparoscopy and Hysteroscopy, Third Edition

Edited by Camran Nezhat, Farr Nezhat and Ceana Nezhat

Excerpt

More information

\section{8 - Barbara J. Page, Jaime Ocampo, Mario Nutis, and Anthony A. Luciano}

55. C Nezhat, F Nezhat. Videolaseroscopy for the treatment of ovarian remnant attached to bowel and ureter Annual Meeting of AAGL November 1990.

56. Nezhat F, Nezhat C, Nezhat CH. Laparoscopic sacral colpopexy for vaginal wall prolapse. Obstet Gynecol. 1994; 84:885-888.

57. Nezhat F, Nezhat C, Levy JS. Laparoscopic treatment of symptomatic diaphragmatic endometriosis: A case report. Fertil Steril. 1992;58:614-616.
58. Nezhat C, Childers J, Nezhat F, et al. Major retroperitoneal vascular injury during laparoscopic surgery. Hum Reprod. 1997; 12:480483.

59. Nezhat C, Winder WK, Nezhat F. Laparoscopic removal of dermoid cysts, Obst Gynecol. 1989;73(2):278-281.

60. Seidman DS, Nezhat C. Letter-to-the-Editor: Is the laparoscopic bubble bursting? The Lancet, Feb 241996.

61. Pappas, Joacobs, NEJM, May 2004. 
Successful operative laparoscopy requires the proper basic and specialized equipment to make difficult procedures technically possible and safe. Most operations can be done with two or three forceps, a suction-irrigator probe, a bipolar electrocoagulator, and a $\mathrm{CO}_{2}$ laser. With the rapid growth of operative laparoscopy, disposable, semireusable, and reusable instruments have become available. In selecting the appropriate instruments, their cost and effectiveness should be considered because too many instruments clutter the field and increase operative time.

With videolaseroscopy, the operation is observed by the surgeon and operating room staff on video monitors. The $\mathrm{CO}_{2}$ laser is used through the operative channel of the laparoscope for cutting and establishing hemostasis of small blood vessels. [1] Electrocoagulation with a bipolar forceps is used to control bleeding from larger vessels. These instruments enable surgeons to increase the diversity of laparoscopic procedures. Some of them have multiple functions, whereas others are specialized. Most are designed to fit through trocar sleeves between $2 \mathrm{~mm}$ and $33 \mathrm{~mm}$ in diameter.

\section{THE BASIC INSTRUMENTS}

\section{The Laparoscope}

The endoscope allows one to view the abdominal and pelvic cavities and is the most important piece of equipment. It must be in optimal condition. Although the diameter of laparoscopes varies from 2 to $12 \mathrm{~mm}$ and the angle of view varies from $0^{\circ}$ to $90^{\circ}$, the most commonly used laparoscopes are straight diagnostic (Figure 2.1A) and angled operative laparoscopes (Figure 2.1B,C). A direct $10-\mathrm{mm}, 0^{\circ}$ diagnostic laparoscope and an $11-\mathrm{mm}, 0^{\circ}$ operative laparoscope with a channel for the $\mathrm{CO}_{2}$ laser are preferable (Figure 2.2A,B). The image transmitted by the diagnostic scope is better. The operative channel requires a reduction in the size of the lens system and the number of fiberoptic bundles. With a Hopkins rod lens system, the shaft of the laparoscope contains quartz rods with concave ends that provide excellent clarity. This type of lens rarely is dislodged during handling. Endoscopes are either rigid or flexible. Most rigid scopes are focused with the camera coupler. With a videoscope (camera and scope together), either there will be a focus control on the scope or the focus will occur automatically inside the camera. The image is magnified and appears larger on the monitor.

Flexible scopes rely on many fiberoptic bundles. As the image is magnified, so are the bundles, making the ends of the bundles visible along with the image. The scopes are relatively fragile, and small cracks allow water to seep through the lens and distort the image.

Another breakthrough in medical cameras is "chip-on-astick," a technology that combines the camera and the scope in one piece of equipment. The camera chip is taken out of the camera head and placed at the distal end of the scope. This technology does away with the optical lenses an image passes through when the chip is in the camera head. Chip-on-a-stick cameras require less light than do standard cameras because light is not lost in the light cord and rod lens.

There are multiple manufacturers of laparoscopes, all of which have slightly different variations. We recommend that you try laparoscopes from different manufacturers so that you can find the most comfortable one for you.

\section{Primary Trocars}

Reusable and disposable trocars are constructed of a combination of metal and plastic (Figure 2.3A,B). A feature common to all of them is a flapper or trumpet valve that is designed to prevent gas leakage as the laparoscope or other instruments are removed from the abdomen. With reusable trocars, this mechanism creates friction on the laparoscope. After a prolonged procedure, the trocar moves with the laparoscope. This phenomenon causes inadvertent removal of the trocar from the abdominal cavity and a loss of pneumoperitoneum. When the spring is removed from the valve, there is less friction and that problem can be avoided. A feature of disposable cannulas is a new stability thread design that provides greater fixation of the abdominal wall. A radially expanding outer sheath has been developed to allow safer trocar insertion (Step, InnerDyne, Sunnyvale, CA). The radially expanding dilation is supposed to leave a $50 \%$ smaller scar while securely anchoring the cannula and virtually eliminating abdominal wall bleeding (Figure 2.4).

Another approach to improving the safety of primary trocar insertion is the observing or optical trocar (Ethicon; Figure 2.3B). The obturator of this trocar is hollow except for a clear plastic conical tip with two external ridges. The trocar-cannula assembly is passed through tissue layers to enter the operative space under direct vision from a $10-\mathrm{mm}$ or a $5-\mathrm{mm} 0^{\circ}$ laparoscope placed into the trocar. Initial experience suggests that this technique represents a safe alternative to Veress needle placement when laparoscopic access could be hazardous or difficult. [2,3] The optical device requires some additional training so that the operator can identify the various anatomic layers upon entry into the abdomen through the contact view. This device is no substitute for proper training, and its cost-effectiveness for an experienced laparoscopist is doubtful.

A fiberglass optic-equipped safety needle has been developed for visually controlled access in laparoscopic procedures. This device can allow immediate diagnosis of small bowel perforation by endoscopy.[4] 
Cambridge University Press

978-0-521-86249-3 - Nezhat's Operative Gynecologic Laparoscopy and Hysteroscopy, Third Edition

Edited by Camran Nezhat, Farr Nezhat and Ceana Nezhat

Excerpt

More information

10 - Jaime Ocampo, Mario Nutis, Camran Nezhat, Ceana Nezhat, and Farr Nezhat

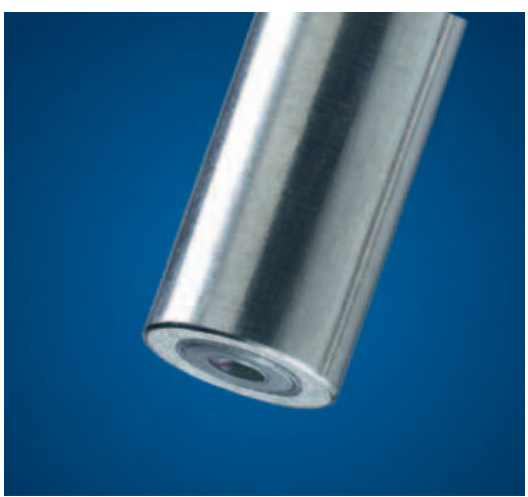

A
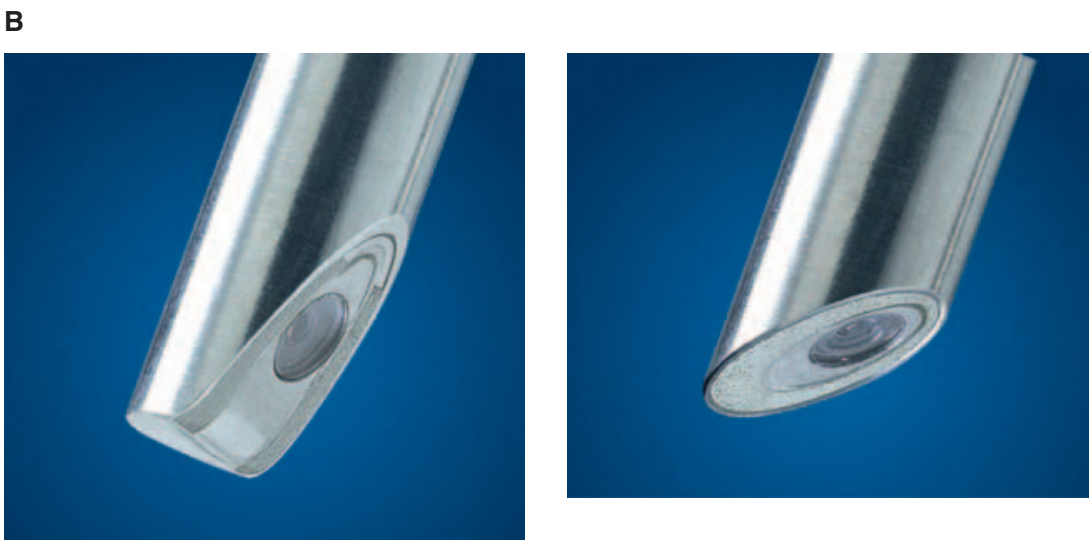

Figure 2.1. (A) A 5-mm straight diagnostic laparoscope. (B) A 10-mm diagnostic laparoscope. (C) Angled laparoscopes.
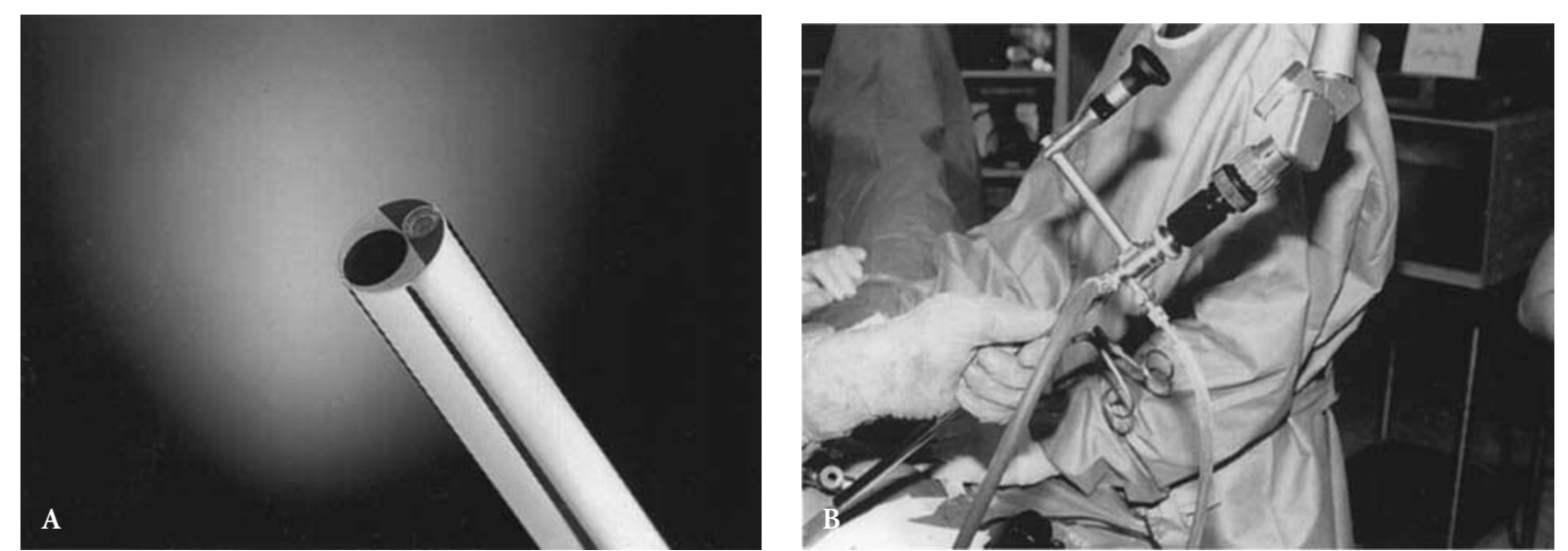

Figure 2.2. (A) The laser laparoscope has two channels: one for the $\mathrm{CO}_{2}$ laser and one for the light source. (B) The $\mathrm{CO}_{2}$ laser is connected to the operative channel of the laparoscope. 